\title{
Interaction of high flux Deuterium/Nitrogen plasmas with Beryllium
}

\author{
T. Dittmar, ${ }^{1, *}$ M. J. Baldwin, ${ }^{1}$ R. P. Doerner,${ }^{1}$ D. Nishijima, ${ }^{1}$ M. Oberkofler, ${ }^{2}$ T. Schwarz-Selinger, ${ }^{2}$ and F. Tabarés ${ }^{3}$ \\ ${ }^{1}$ Center for Energy Research, University of California-San Diego, \\ 9500 Gilman Dr., San Diego, CA 92093-0417, USA \\ ${ }^{2}$ Max-Planck-Institut für Plasmaphysik, EURATOM Association, 85748 Garching, Germany \\ ${ }^{3}$ Asociatión EURATOM/CIEMAT para Fusión, Avda Complutense 22, 28040 Madrid, Spain
}

\begin{abstract}
Before nitrogen can be used as radiator for edge plasma temperature control in experiments with beryllium as the wall material, the compatibility of nitrogen containing plasma with beryllium has to be tested. Therefore beryllium samples were exposed to a variety of mixed $\mathrm{N}_{2} / \mathrm{D}_{2}$ plasmas in PISCES-B and codeposits from the sputtered material were collected. It was found that introducing $\mathrm{N}_{2}$ to a $\mathrm{D}_{2}$-plasma reduces Be erosion significantly but recovery to the pre- $\mathrm{N}_{2}$ levels is possible in pure $\mathrm{D}_{2}$ plasma. Berylliated vessel walls can be a reservoir for $\mathrm{N}_{2}$ and chemical processes probably play a significant role during nitriding and $\mathrm{N}_{2}$ removal. Nitrided target samples remain conductive and did not lead to additional arcing but codeposits are insulating. Thermal desorption measurements of nitrided and un-nitrided target samples were comparable, while codeposits show a slightly reduced D retention. However D release for both target and codeposits is shifted $\approx 100 \mathrm{~K}$ to higher temperatures, above $510 \mathrm{~K}$.
\end{abstract}

PACS numbers: $77.84 . \mathrm{Bw} 52.40 . \mathrm{Hf}$

\section{INTRODUCTION}

Reliable edge plasma temperature control through radiative cooling is considered crucial to protect plasma facing components in high performance discharges in current and future fusion devices. Positive results from ASDEX Upgrade with nitrogen $\left(\mathrm{N}_{2}\right)$ seeding in an alltungsten tokamak[1] lead to the question whether $\mathrm{N}_{2}$ seeding would be a viable option within the ITER-likewall project at JET[2] or in ITER. One of the open issues is the compatibility of $\mathrm{N}_{2}$ seeding with Beryllium (Be) as the wall material. This is because some fraction of the nitrogen injected in the divertor region will be transported to the main chamber wall where it can be codeposited or implanted. Codeposition of nitrogen with $\mathrm{Be}$ is also expected in deposition dominated regions in the divertor. It has been shown that Be forms a stable nitride $\left(\mathrm{Be}_{3} \mathrm{~N}_{2}\right)$ with an optical band gap of $\approx 4 \mathrm{eV}[3,4]$ and is essentially insulating. Since insulating layers increase the risk of detrimental arcing, the formation of such layers either by ion implantation, or by codeposition, could limit the use of $\mathrm{N}$ seeding in the presence of a Be first wall. Understanding the interaction of $\mathrm{N}_{2}$ with $\mathrm{Be}$ is therefore important to make reliable predictions regarding $\mathrm{N}_{2}$ seeding in tokamaks.

In a recent study of bombarding Be with energetic deuterium and nitrogen ions, the formation of mixed $\mathrm{Be}_{x} \mathrm{~N}_{y}$ compounds was observed [5]. These compounds were thermally stable and showed no nitrogen release up to $1000 \mathrm{~K}$. However, ion beam experiments alone are probably insufficient to predict the influence of $\mathrm{N}_{2}$ in a tokamak containing Be since energetic particles and radiation from a plasma can open additional chemical pathways

*Electronic address: tdittmar@ucsd.edu (e.g. ammonia production). It is therefore important to study the interaction of nitrogen with beryllium directly under fusion relevant plasma conditions. The linear divertor plasma simulator PISCES-B [6, 7], capable of handling berylliated samples, is ideally suited for these experiments. Directly exposed beryllium samples and codeposits from the sputtered material were produced from a variety of mixed $\mathrm{N}_{2} / \mathrm{D}_{2}$ plasmas. This paper reports on the first results of exposure and post mortem analysis of these samples regarding the effect of the nitrogen on target erosion and the $\mathrm{D}_{2}$ retention in targets and codeposits.

\section{EXPERIMENTAL METHODS}

All samples were exposed in the PISCES-B device using the setup described in [6, 7]. Be samples were exposed at the target position and sputtered material was collected on tungsten or tungsten coated graphite disks on the witness plate manipulator. The plasmas were either generated in pure $\mathrm{D}_{2}$ or in $\mathrm{N}_{2} / \mathrm{D}_{2}$ mixtures feed directly into the plasma source. For the gas mixtures the neutral partial pressure fractions were measured with a capacitive pressure gauge prior to plasma operation (cold plasma cathode) and set from 0.6 to $15 \%$ $\mathrm{N}_{2}$. Plasma conditions near the target were measured with a reciprocating double Langmuir probe. Typical values were electron densities $\mathrm{n}_{\mathrm{e}}=2-3 \times 10^{18} \mathrm{~m}^{-3}$, electron temperatures $\mathrm{T}_{\mathrm{e}}=4-12 \mathrm{eV}$, and ion fluxes about $2-4 \times 10^{22} \mathrm{~m}^{-2} \mathrm{~s}^{-1}$. Fluences of $1.5-6 \times 10^{26} \mathrm{~m}^{-2}$ were typical for exposures. Both the target and witness plate sample holders were actively cooled and the sample temperatures were measured with thermocouples on the backside. Typical target temperatures ranged from $310 \mathrm{~K}$ to $420 \mathrm{~K}$ and the witness plate was kept between $290 \mathrm{~K}$ and $310 \mathrm{~K}$. 
Two different kinds of experiments were performed: (i) target and witness plate samples were exposed to steady state plasma or (ii) targets experienced different plasma conditions during a single exposure. In the first, absolute erosion rates (from net-mass change during exposure) and $\mathrm{D}_{2}$ retention were examined. In the second, changing exposure conditions were utilized to examine relative erosion rates using optical emission spectroscopy (OES): The radial, line-of-sight integrated emission of different species (i.a. BeI (457.3 nm), BeD (498 nm), $\mathrm{N}_{2}^{+}$ $(427.8 \mathrm{~nm})$, and ND $(335.5 \mathrm{~nm}))$ in the target region was observed with a Czerny-Turner type spectrometer (focal length: $500 \mathrm{~mm}$, Dove prism, and camera to measure axial emission profiles). A camera (VIS, IDS systems uEye, $10 \mathrm{~Hz}$ frame rate) looking at the target surface, was used to infer changes of the target morphology and recorded arcing events. In addition to the optical diagnostics, the neutral gas composition in the vacuum chamber was monitored with mass spectrometry (MS) installed in a pumping duct (Ferran Scientific MPA6/65C RGA).

After plasma exposure selected target samples were transferred in vacuo to a surface analysis station (PHI Systems) to be analyzed with X-ray photoelectron spectroscopy (XPS) and Auger electron spectroscopy (AES). Both target and witness plate samples were analyzed exsitu using a combined SEM/EDX (JEOL-JSM 6360) station to study elemental composition and surface morphology after the exposure. Deuterium retention in the samples was measured using programed thermal desorption mass spectroscopy (TDS) in a infrared heated quartztube oven. Typically, a linear temperature ramp with $0.3 \mathrm{~K} / \mathrm{s}$ up to $923 \mathrm{~K}$ and a hold time of $30 \mathrm{~min}$ at the maximum temperature were used. Partial pressures during desorption were recorded with a high resolution MKS Microvision $6 \mathrm{u}$ RGA and a Stanford Research Systems RGA100.

\section{RESULTS}

The addition of up to $10 \%$ of $\mathrm{N}_{2}$ to the plasma had only insignificant effects on the plasma performance. Plasma source voltage and current remained unchanged and the $\mathrm{D}_{\gamma}$ emission showed no significant variation due to the $\mathrm{N}_{2}$ injection. The double-probe measurements showed no significant change in particle fluxes, electron density, and electron temperature. After the injection of the nitrogen the sample temperature equilibrated usually 10$20 \mathrm{~K}$ lower than in the pure $\mathrm{D}_{2}$ case. The formation of a thin nitrogen containing layer on the target samples was confirmed by XPS and AES and these layers on the targets were found to be still conductive when tested exsitu with a two contact probe and ohmmeter. This is in contrast to the thicker codeposits on the witness plate samples, which were found to be insulating.

At the beginning of exposures, arcing on the target samples was observed both in pure $\mathrm{D}_{2}$ and mixed $\mathrm{N}_{2} / \mathrm{D}_{2}$ plasmas. Initial analysis of the camera data showed no influence of the $\mathrm{N}_{2}$ concentration on arcing frequency and duration. Therefore, it is plausible to assume that the observed arcing is mainly due to the natural oxide layer on the Be targets but influences of the nitride layer can not be excluded from the current data. However, it should be noted that nitrided samples showed no stronger tendency to form arcs than samples with the natural oxide layer.

Sputtering yields of $4.5 \times 10^{-3}$ per ion at $E_{\text {ion }}=80 \mathrm{eV}$ and $1.5 \times 10^{-3}$ per ion at $30 \mathrm{eV}$ were calculated from mass loss measurements of the samples exposed to steady state plasma conditions assuming single ionized ions and $E_{\text {ion }} \approx V_{\text {bias }}-2 k_{B} T_{e}[8]$. For the the pure deuterium plasmas $\mathrm{D}_{3}^{+}$is assumed as being the dominant ion species [9] - Adding $10 \% \mathrm{~N}_{2}$ to the discharge reduced the target erosion rates at $E_{\mathrm{ion}}=80 \mathrm{eV}$ by a factor of $\approx 2$ to a value of $2.4 \times 10^{-3}$ per incident ion (all ion species). For $30 \mathrm{eV}$ ions, the addition of $10 \% \mathrm{~N}_{2}$ resulted in a mass loss at or below our detection limit. Similar results were obtained for exposures with $4 \% \mathrm{~N}_{2}$.

Figure 1 shows OES and MS data of a target nitriding at $1.4 \% \mathrm{~N}_{2}$ and subsequent recovery after closing the $\mathrm{N}_{2}$ feed. Panels a) and b) show line-of-sight integrated optical emissions of BeI and $\mathrm{N}_{2}^{+}$directly in front of the target and for the bulk plasma (100mm upstream). All emission signals shown are normalized to the $\mathrm{D}_{\gamma}$ emission to account for any variation in the plasma conditions while the concentration of the nitrogen was increased in the plasma. Panel c) shows neutral gas mass spectrometry traces for masses $4\left(\mathrm{D}_{2}, \mathrm{He}\right), 18\left(\mathrm{H}_{2} \mathrm{O}, \mathrm{ND}_{2}\right), 20\left(\mathrm{D}_{2} \mathrm{O}\right.$, $\left.\mathrm{ND}_{3}\right)$ and $28\left(\mathrm{~N}_{2}\right)$. During the first $240 \mathrm{~s}$ only $\mathrm{D}_{2}$ was injected. Nevertheless, the mass spectrometry shows a small amount of $\mathrm{N}_{2}$ and $\mathrm{ND}_{3}$ in the neutral gas which is attributed to the $\mathrm{N}_{2}$ inventory from previous experiments on the chamber wall. At $\mathrm{t}=240 \mathrm{~s}$ the $\mathrm{N}_{2}$ injection started. Immediately the Be erosion decreased, as seen by the reduction of the BeI emission which stabilizes after $\approx 100 \mathrm{~s}$. This reduced erosion is probably due the formation of a thin nitride layer, being in a dynamic equilibrium of constant formation and erosion. Whether this layer is simply more resistant to chemical or physical sputtering, or if the insulating properties of the beryllium nitride generate a potential drop reducing the energy of the incident ions, has still to be determined.

The $\mathrm{N}_{2}$ content in the plasma and neutral gas rises during the duration of the $\mathrm{N}_{2}$ injection. The rise time of the nitrogen species during plasma operation is also much longer compared to gas puffing experiments without plasma. This is explained by additional chemical "pumping" of the berylliated walls of PISCES-B which have a much larger area than the target structure. Note that the plasma column is not in direct contact with the chamber walls and this reaction has to be driven by radiation or neutral radicals. At $\mathrm{t}=600 \mathrm{~s}$ the $\mathrm{N}_{2}$ was switched off. Recovery of the surface properties took longer than the initial nitriding, but the BeI emmision eventually recovered to the same levels as prior to the $\mathrm{N}_{2}$ injection. The recovery time is likely to be limited by the pump out 
optical emmision spectroscopy:
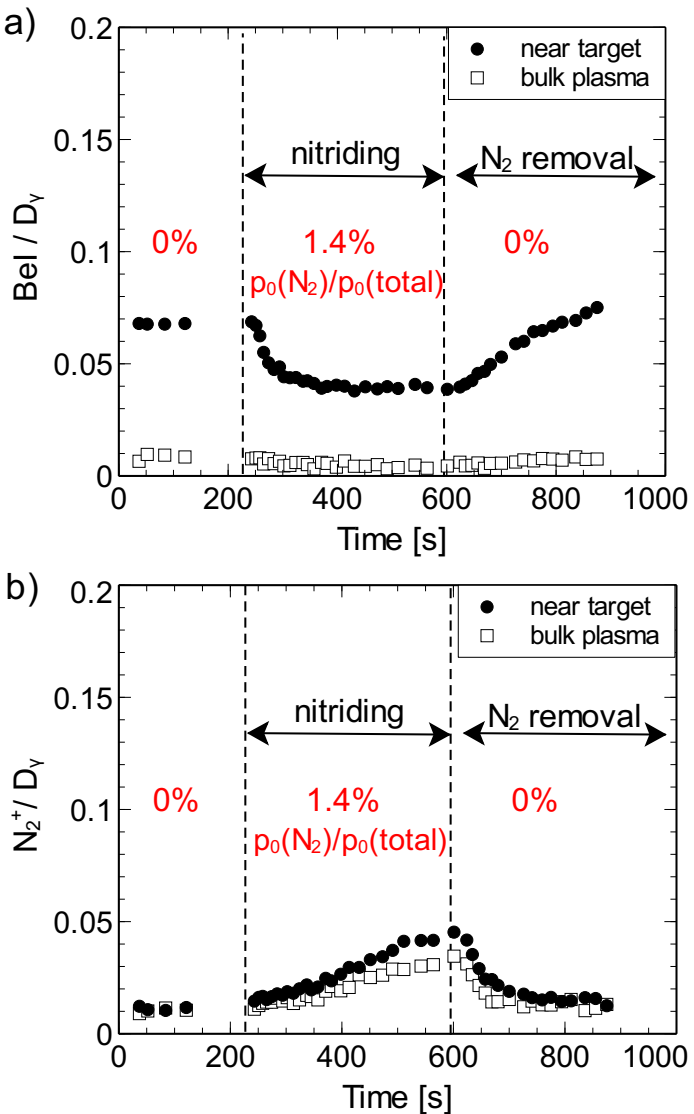

mass spectrometry:

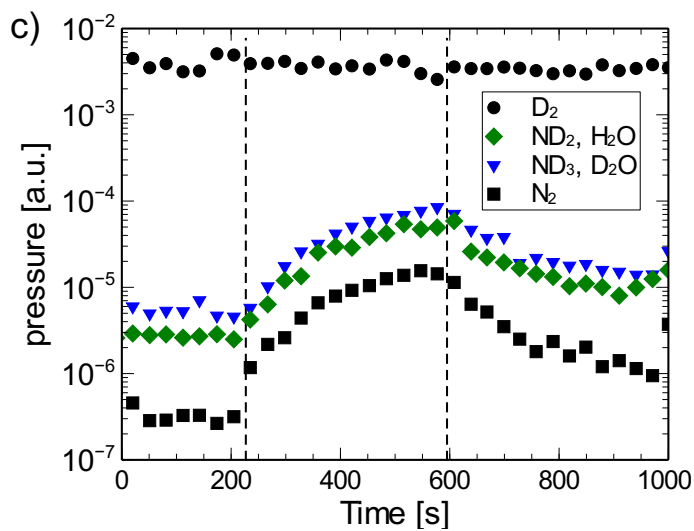

Figure 1: Nitriding and recovery: normalized optical emissions of (panel a) BeI and (b) $\mathrm{N}_{2}^{+}$directly in front of the target and for the bulk plasma $\left(\mathrm{d}_{\text {target }}=100\right.$ $\mathrm{mm})$. Neutral gas mass spectrometry traces (c) of the masses $4\left(\mathrm{D}_{2}, \mathrm{He}\right), 18\left(\mathrm{ND}_{2}, \mathrm{H}_{2} \mathrm{O}\right), 20\left(\mathrm{ND}_{3}, \mathrm{D}_{2} \mathrm{O}\right)$ and

$28\left(\mathrm{~N}_{2}\right)$. The exposure conditions were

$\Gamma_{\mathrm{D}^{+}}=2 \times 10^{22} \mathrm{~m}^{-2} \mathrm{~s}^{-1}, \mathrm{~T}_{\text {Target }}=350 \mathrm{~K}, \mathrm{~V}_{\text {bias }}=-75 \mathrm{~V}$ resulting in $\mathrm{E}_{\mathrm{ions}} \approx 50 \mathrm{eV}$ during the nitriding and

$\Gamma_{\mathrm{D}^{+}}=2 \times 10^{22} \mathrm{~m}^{-2} \mathrm{~s}^{-1}, \mathrm{~T}_{\text {Target }}=410 \mathrm{~K}$,

$\mathrm{V}_{\text {bias }}=-120 \mathrm{~V}$ resp. $\mathrm{E}_{\text {ions }} \approx 95 \mathrm{eV}$ during the $\mathrm{N}_{2}$ removal phase. of the $\mathrm{N}_{2}$ from the chamber and the re-supply of nitrogen species from the chamber walls: even after $400 \mathrm{~s}$ of operation with only the $\mathrm{D}_{2}$ flow-controller open, the amount of nitrogen species in the neutral gas is still larger than at the beginning of the experiment.

In a separate experiment the influence of the $\mathrm{N}_{2}$ concentration was examined. Figure $\sim 2$ shows optical emissions for $\mathrm{BeD}, \mathrm{BeI}$ and $\mathrm{N}_{2}^{+}$both directly in front and $100 \mathrm{~mm}$ upstream of the target for different concentrations of $\mathrm{N}_{2}$ in the fill gas. During the first $2700 \mathrm{~s}$ of the exposure (region A) PISCES was operated in a pure $\mathrm{D}_{2}$ plasma. During this time the emission of both eroded Be species decayed while the observation with the target camera showed a change from a shiny, highly reflective to a blackened target surface associated with the development of surface morphology. At $\mathrm{t}=2700 \mathrm{~s} 0.7 \% \mathrm{~N}_{2}$ was introduced into the filling gas resulting in a slight reduction of the Be erosion but no significant increase of the $\mathrm{N}_{2}^{+}$emission due to the $\mathrm{N}_{2}$-pumping of the chamber walls (region B).

In the first $1000 \mathrm{~s}$ after increasing the amount of $\mathrm{N}_{2}$ to $1.4 \%(\mathrm{t}=3500 \mathrm{~s}$, region $\mathrm{C})$ the $\mathrm{N}_{2}^{+}$emission remained low while the Be emissions decreased slowly. The appearance of $\mathrm{N}_{2}^{+}$emission in the bulk plasma around $4500 \mathrm{~s}$ is probably an indication of a $\mathrm{N}_{2}$ saturation on the vessel walls and was accompanied by a significant drop in the Be erosion.

After the $\mathrm{N}_{2}$ flow was switched off at $\mathrm{t} \approx 5400 \mathrm{~s}$, the Be erosion signals recovered to the pre-nitrogen levels (region $\mathrm{D}$ ). Further increases of the $\mathrm{N}_{2}$ neutral pressure up to $12 \%$ (regions $\mathrm{E}-\mathrm{G}$ ) showed no additional decrease of the emission signals from $\mathrm{Be}$ and $\mathrm{BeD}$ within the experimental uncertainties although the emission signal from $\mathrm{N}_{2}^{+}$confirmed the increased $\mathrm{N}$ content in the plasma.

In contrast to the recovery in $\mathrm{D}_{2}$, helium plasmas showed little to no effect in removing the nitrogen from the target sample and the machine. Although an absolute comparison with the recovery in D plasma is complicated due to the difference in densities and ion energy distributions, these results indicate that chemical processes, possibly involving ammonia, could play a significant role in the removal of the nitrogen from the Be surface.

Lastly, the influence of $\mathrm{N}_{2}$ injection on fuel retention was examined. Figure $\sim 3$ shows TDS spectra of witness plate and target samples. The TDS spectra of target samples exposed to pure $\mathrm{D}_{2}$ (subfigure a) and to mixed $\mathrm{N}_{2} / \mathrm{D}_{2}$ plasma (b) show very similar shapes of the desorption peaks, although the desorption temperatures are shifted $\approx 100 \mathrm{~K}$ to higher temperatures for the nitrided samples. Nearly all of the deuterium is desorbed as $\mathrm{D}_{2}$ or HD, with only small contributions of $\mathrm{ND}_{3}$ or $\mathrm{D}_{2} \mathrm{O}$. The total $\mathrm{D}_{2}$ retention in both target samples, with $3.2 \times 10^{17}$ atoms $\mathrm{D}$ for the pure deuterium and $2.7 \times 10^{17}$ atoms $\mathrm{D}$ for the nitrided case, is the same within the reproducibility of the exposures. The desorption spectrum of the nitrided codeposit (subfigure d) shows the same shift in the release temperatures as the nitrided target sample, but also an overall temperature broadening of 

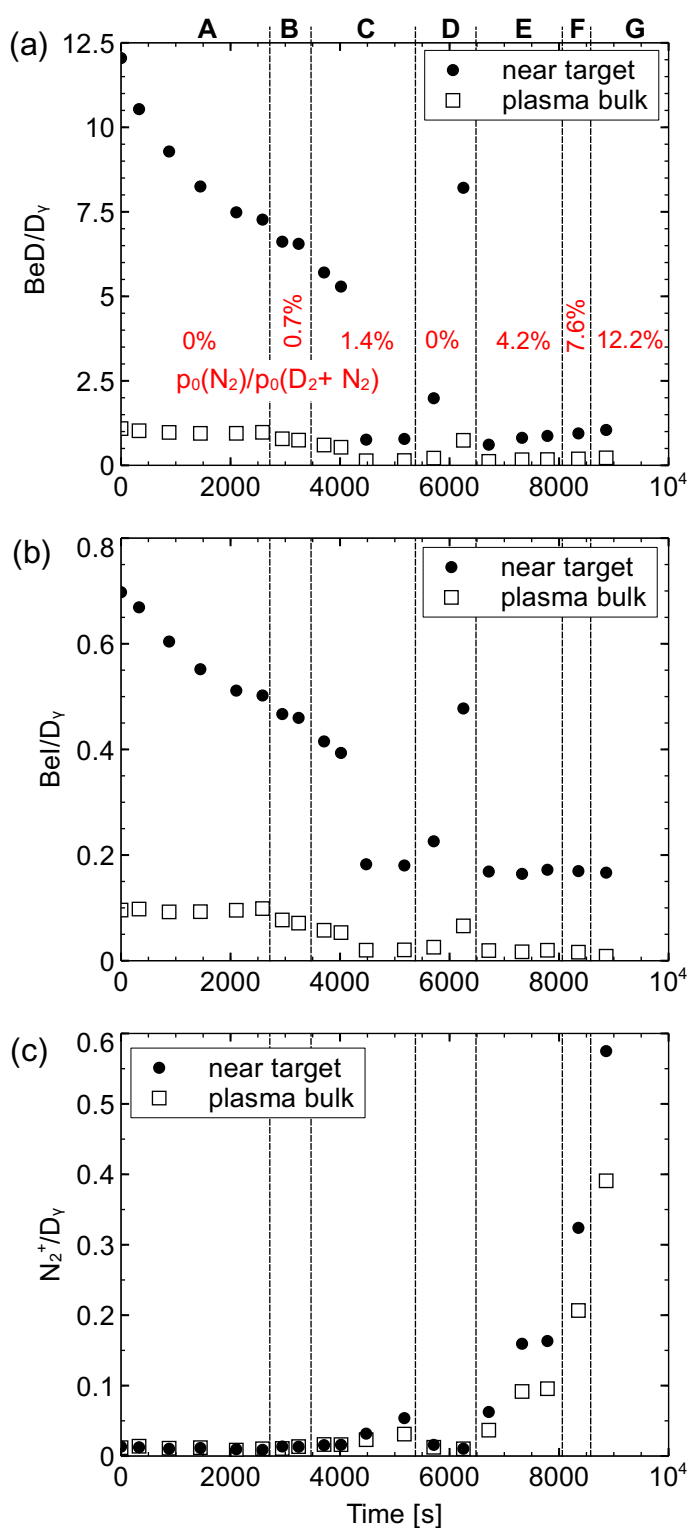

Figure 2: Effect of $\mathrm{N}_{2}$ concentration in the plasma: radially plasma column integrated emmisions of (a)

$\mathrm{BeD}$, (b) BeI and (c) $\mathrm{N}_{2}^{+}$for plasmas with different $\mathrm{N}_{2}$ concentrations. The exposure conditions were $\Gamma_{\mathrm{D}^{+}}=3 \times 10^{22} \mathrm{~m}^{-2} \mathrm{~s}^{-1}, \mathrm{~T}_{\text {Target }}=330 \mathrm{~K}$, target bias $\mathrm{V}_{\text {bias }}=-100 \mathrm{~V}$ resulting in $\mathrm{E}_{\mathrm{ions}} \approx 80 \mathrm{eV}$.

the release peak (similar to the observations on codeposits collected in argon-seeded plasma De Temmerman et al. [10]) . , The evaluation of the retention in the codeposits is more complex as the total amount of retained $\mathrm{D}_{2}$ depends both on the thickness of the deposited layer and the $\mathrm{D} / \mathrm{Be}$ ratio within the deposit. Since the thickness of the codeposited films on the witness plate samples was comparable to the substrate roughness, a precise thickness measurement was not possible. Assuming that eroded Be from the target is the main driver for the codeposition it seems feasible to normalize the retention in the codeposits to the mass loss of the target samples. Using the data from the target samples, this normalization results in $\mathrm{a} \approx 20 \%$ lower retention in the nitrided samples, but this result should not be overemphasized as considerable uncertainties due to possible differences in growth rates and plasma conditions exist.

\section{DISCUSSION AND CONCLUSIONS}

The results of first experiments regarding the interaction of mixed $\mathrm{N}_{2} / \mathrm{D}_{2}$ plasmas with beryllium in PISCES$\mathrm{B}$ are described: injecting varying amounts of nitrogen showed no severe consequences for plasma operation but strong nitrogen pumping and wall-reservoir effects are observed. This could be explained as plasma enhanced chemical reactions of nitrogen species with the berylliated walls of the PISCES vacuum vessel. Nitrogen pumping and the wall reservoir might change the effectiveness of $\mathrm{N}_{2}$ injection in the ITER-like-wall experiments in JET.

Although arcing was observed at the directly plasma wetted targets in the beginning of exposures, nitriding is found to be not more detrimental than the natural oxide layer of the beryllium targets. The existence of thin nitrogen containing layers on the targets was verified with XPS and AES. The thin nitride layers of the targets remain conductive, but the thicker layers of nitrided codeposits are insulating. In a tokamak, these insulating codeposits could be potential source of arcing.

Small amounts of nitrogen in the source gas effectively reduced the erosion of beryllium, especially at ion energies $<80 \mathrm{eV}$. Recovery from a nitrided surface is possible in deuterium plasmas. The relatively slow recovery from nitrided Be surfaces in helium plasma hints at the important role chemical erosion might play in the nitriding and recovery.

Thermal desorption of target samples show no significant change in $D_{2}$ retention when exposed to mixed $\mathrm{N}_{2} / \mathrm{D}_{2}$ plasmas whereas codeposits exhibit a slightly lower $\mathrm{D}_{2}$ retention. However, the main release peaks both for target samples and codeposits show a significant shift $(\approx 100 \mathrm{~K})$ to higher temperature, above the $510 \mathrm{~K}$ main chamber bake-out temperature of the current ITER design.

\section{Acknowledgments}

The authors would like to thank the skillful and dedicated support from the technical staff and the beryllium enclosure personel of the PISCES lab. This work was supported by US Departement of Energy grant no. DEFG02-07ER54912 and by US-DOE and EFDA as part of an ongoing US-EU collaboration on mixed materials. The views and opinions expressed herein do not necessarily reflect those of the European Commission. 


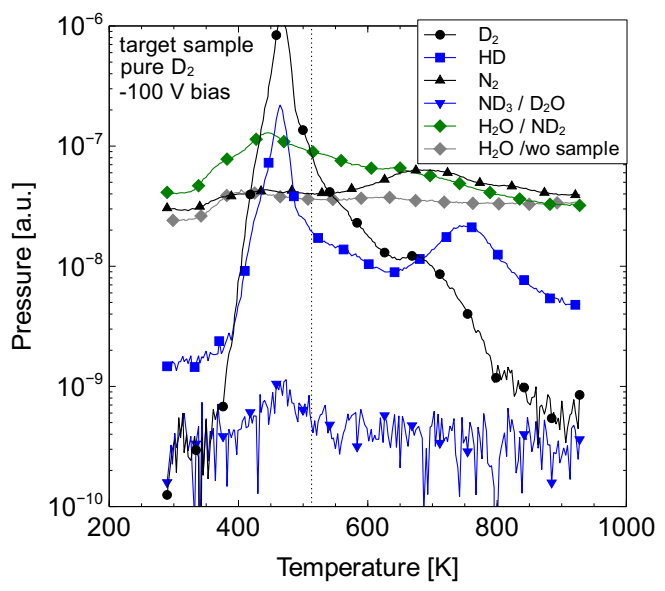

(a) target sample, pure $\mathrm{D}_{2}$ plasma

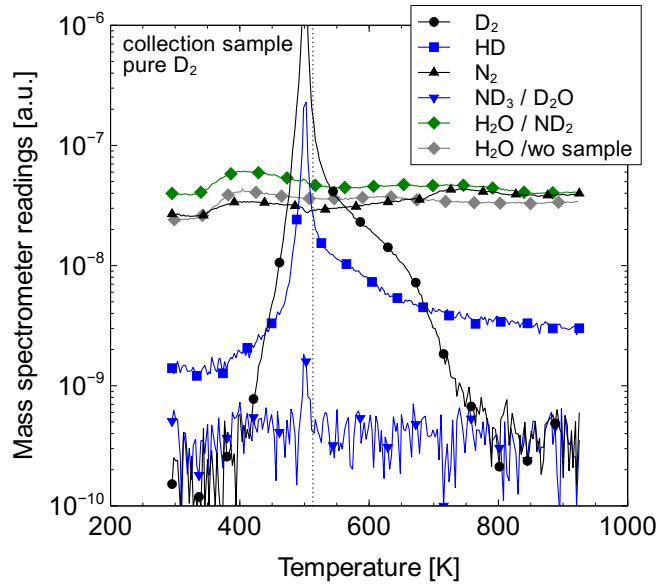

(c) witness plate sample, pure $\mathrm{D}_{2}$ plasma

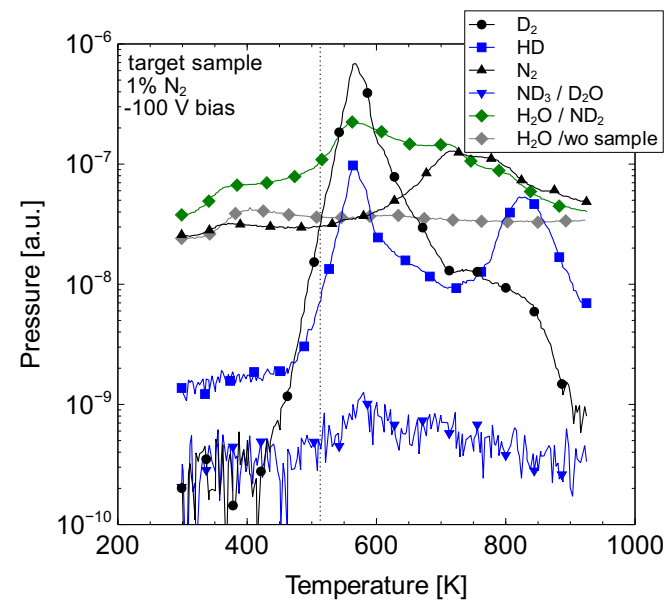

(b) target sample, $\mathrm{N}_{2} / \mathrm{D}_{2}$ plasma

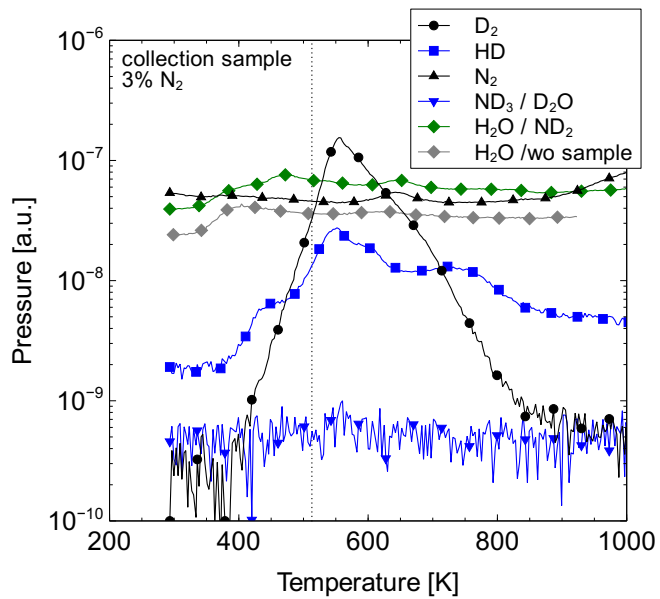

(d) witness plate sample, $\mathrm{N}_{2} / \mathrm{D}_{2}$ plasma

Figure 3: Thermal desorption spectra of target (top) and wittness plate (bottom figures) samples exposed to pure

$\mathrm{D}_{2}$ (left) and mixed $\mathrm{D}_{2} / \mathrm{N}_{2}$ (right figures) plasmas. The linear temperature ramp was $0.3 \mathrm{Ks}^{-1}$. Traces of the masses $3(\mathrm{HD}), 4\left(\mathrm{D}_{2}\right), 18\left(\mathrm{ND}_{2}, \mathrm{H}_{2} \mathrm{O}\right), 20\left(\mathrm{ND}_{3}, \mathrm{D}_{2} \mathrm{O}\right)$ and $28\left(\mathrm{~N}_{2}\right)$ are shown. To verify the temperature scale, a trace of mass $18\left(\mathrm{H}_{2} \mathrm{O}\right)$ of a outgassing of the empty quartz-tube oven is included in each figure. The dashed vertical lines at $513 \mathrm{~K}$ denotes the maximum main wall bake-out temperature in ITER.

[1] A. Kallenbach, R. Dux, M. Mayer, R. Neu, T. Putterich, V. Bobkov, J. C. Fuchs, T. Eich, L. Giannone, O. Gruber, A. Herrmann, L. D. Horton, C. F. Maggi, H. Meister, H. W. Muller, V. Rohde, A. Sips, A. Stabler, and J. Stober. Non-boronized compared with boronized operation of ASDEX Upgrade with full-tungsten plasma facing components. Nuclear Fusion, 49(4):045007, April 2009. doi: $10.1088 / 0029-5515 / 49 / 4 / 045007$.

[2] G. F. Matthews, P. Edwards, T. Hirai, M. Kear, A. Lioure, P. Lomas, A. Loving, C. Lungu, H. Maier, P. Mertens, D. Neilson, R. Neu, J. Pamela, V. Philipps, G. Piazza, V. Riccardo, M. Rubel, C. Ruset, E. Villedieu, and M. Way. Overview of the ITER-like wall project. Physica Scripta, T128:137-143, March 2007. doi: 10.
1088/0031-8949/2007/T128/027.

[3] M. G. M. Armenta, A. Reyes-Serrato, and M. A. Borja. $\mathrm{Ab}$ initio determination of the electronic structure of beryllium-, aluminum-, and magnesium-nitrides: A comparative study. Physical Review B, 62(8):4890-4898, August 2000 .

[4] G. Soto, J. A. Díaz, R. Machorro, A. Reyes-Serrato, and W. de la Cruz. Beryllium nitride thin film grown by reactive laser ablation. Materials Letters, 52(1-2):29 - 33, 2002. ISSN 0167-577X. doi: DOI:10.1016/S0167-577X(01)00360-3. URL http://www.sciencedirect.com/science/article/ $\mathrm{pii/S0167577 \times 01003603.}$

[5] M. Oberkofler and C. Linsmeier. Properties of nitrogen- 
implanted beryllium and its interaction with energetic deuterium. Nuclear Fusion, 50(12):125001, December 2010. doi: $10.1088 / 0029-5515 / 50 / 12 / 125001$.

[6] M. J. Baldwin, K. Schmid, R. P. Doerner, A. Wiltner, R. Seraydarian, and C. Linsmeier. Composition and hydrogen isotope retention analysis of co-deposited c/be layers. Journal of Nuclear Materials, 337(1-3):590-594, March 2005. doi: 10.1016/j.jnucmat.2004.09.043.

[7] R. Doerner and C. Mays. Beryllium dust generation resulting from plasma bombardment. Fusion Engineering and Design, 37(2):325-331, September 1997.

[8] B. LaBombard, R. W. Conn, Y. Hirooka, R. Lehmer, W. K. Leung, R. E. Nygren, Y. Ra, G. Tanan, and K. S. Chung. Presheath profiles in simulated tokamak edge plasmas. Journal of Nuclear Materials, 162:314321, April 1989.

[9] E. M. Hollmann and A. Y. Pigarov. Measurement and modeling of molecular ion concentrations in a hydrogen reflex-arc discharge. Physics of Plasmas, 9(10):43304339, October 2002. doi: 10.1063/1.1503070.

[10] G. De Temmerman, M. J. Baldwin, R. P. Doerner, D. Nishijima, R. Seraydarian, and K. Schmid. Insight into the co-deposition of deuterium with beryllium: Influence of the deposition conditions on the deuterium retention and release. Journal of Nuclear Materials, 390-91: 564-567, June 2009. doi: 10.1016/j.jnucmat.2009.01.102. 